\title{
Allometric scaling of maximum metabolic rate: the influence of temperature
}

\author{
C. R. White ${ }^{*, 1,2}$, J. S. Terblanche ${ }^{3}$, A. P. Kabat ${ }^{1}$, T. M. Blackburn ${ }^{4}$, S. L. Chown $^{3}$ and P. J. Butler ${ }^{1}$ \\ ${ }^{1}$ Centre for Ornithology, School of Biosciences, The University of Birmingham, Edgbaston, Birmingham B15 2TT, UK; \\ ${ }^{2}$ School of Integrative Biology, The University of Queensland, St Lucia, 4072 QLD, Australia; ${ }^{3}$ Centre for Invasion Biology, \\ Department of Botany and Zoology, Stellenbosch University, Private Bag X1, Matieland 7602, South Africa; and ${ }^{4}$ Institute \\ of Zoology, Zoological Society of London, Regent's Park, London NW1 4RY, UK
}

\begin{abstract}
Summary
1. Maximum aerobic metabolic rate, measured in terms of rate of oxygen consumption during exercise $\left(\dot{\mathrm{V}}_{\mathrm{O}_{2} \max }\right)$, is well known to scale to body mass $(M)$ with an exponent greater than the value of 0.75 predicted by models based on the geometry of systems that supply nutrients.

2. Recently, the observed scaling for $\dot{\mathrm{V}}_{\mathrm{O}_{2} \max }\left(\propto M^{0.872}\right)$ has been hypothesized to arise because of the temperature dependence of biological processes, and because large species show a greater increase in muscle temperature when exercising than do small species.

3. Based on this hypothesis, we predicted that $\dot{\mathrm{V}}_{\mathrm{O}_{2} \max }$ will be positively related to ambient temperature, because heat loss is restricted at high temperatures and body temperature is likely to be elevated to a greater extent than during exercise in the cold.

4. This prediction was tested using a comparative phylogenetic generalized least-squares (PGLS) approach, and 34 measurements of six species of rodent $(20 \cdot 5-939 \mathrm{~g})$ maximally exercising at temperatures from -16 to $30^{\circ} \mathrm{C}$.

5. $\dot{\mathrm{V}}_{\mathrm{O}_{2} \max }$ is unrelated to testing temperature, but is negatively related to acclimation temperature. We conclude that prolonged cold exposure increases exercise-induced $\dot{\mathrm{V}}_{\mathrm{O}_{2} \max }$ by acting as a form of aerobic training in mammals, and that elevated muscle temperatures of large species do not explain the scaling of $\dot{\mathrm{V}}_{\mathrm{O}_{2} \max }$ across taxa.
\end{abstract}

Key-words: Metabolic theory of ecology, acclimation, plasticity, aerobic capacity

\section{Introduction}

Recent theoretical evidence based upon the geometry of nutrient supply networks has provided an explanation for the long-held notion that metabolic rate is proportional to body mass $(M)$ raised to the power of $0 \cdot 75$ (West, Brown \& Enquist 1997; Banavar, Maritan \& Rinaldo 1999), and two recent meta-analyses have supported a universal exponent of 0.75 (Savage et al. 2004; Farrell-Gray \& Gotelli 2005). However, exceptions to the ubiquity of quarter-power metabolic scaling have been reported for insects, fish, amphibians, birds and mammals (Bokma 2004; McKechnie \& Wolf 2004; White \& Seymour 2005a; McKechnie, Freckleton \& Jetz 2006; White, Phillips \& Seymour 2006b; Chown et al. 2007). Two other meta-analyses failed to find support for a universal metabolic scaling exponent of 0.75 (Glazier 2005; White, Cassey \& Blackburn 2007), while Farrell-Gray \& Gotelli (2005) noted that a universal exponent was not supported for poikilotherms.

*Correspondence author. E-mail: craig.white@uq.edu.au
Scaling exponents have also been shown to vary systematically with taxonomy (Hayssen \& Lacy 1985), food habits (McNab 1988), age (Riisgård 1998), zoogeography (Lovegrove 2000), metabolic level (White \& Seymour 2005a) and captivity (McKechnie et al. 2006).

One of the most supported deviations from quarter-power metabolic scaling involves the maximal rate of oxygen consumption $\left(\dot{\mathrm{V}}_{\mathrm{O}_{2} \text { max }}\right)$. Most agree that this does not scale with an exponent of $0 \cdot 75$, but rather with one close to $0 \cdot 87$ (Savage et al. 2004; Weibel et al. 2004; White \& Seymour 2005a). Gillooly \& Allen (2007) recently linked this scaling of $\dot{\mathrm{V}}_{\mathrm{O}_{2} \max }$ to the predictions of the nutrient supply network models and a model of the universal temperature dependence (UTD) of metabolism (Gillooly et al. 2001). They reported that the deviation of $\dot{\mathrm{V}}_{\mathrm{O}_{2} \max }$ from 0.75 scaling can be explained by the observation that changes in muscle temperature from rest to maximal activity are greater in larger than in smaller mammals. Their model suggests that the elevated body temperature arising as a consequence of exercise results in an increase in rate of oxygen consumption $\left(\dot{\mathrm{V}}_{\mathrm{O}_{2}}\right)$, and therefore $\dot{\mathrm{V}}_{\mathrm{O}_{2} \max }$, 
due to the temperature dependence of biological processes. Because the magnitude of the exercise-induced increase in temperature is positively related to body mass, the increase in $\dot{\mathrm{V}}_{\mathrm{O}_{2}}$ attributable to the rise in temperature is also positively related to body mass. Thus, the scaling exponent of $\dot{\mathrm{V}}_{\mathrm{O}_{2} \text { max }}$ is elevated above the value that would be expected if body temperature remained constant throughout exercise. Gillooly \& Allen (2007) also suggest that the steeper scaling of exerciseinduced $\dot{\mathrm{V}}_{\mathrm{O}_{2} \max }$ compared to cold-induced $\dot{\mathrm{V}}_{\mathrm{O}_{2} \max }$ (Hinds \& Rice-Warner 1992; Hinds et al. 1993; White \& Seymour 2005a) might arise due to increases in muscle temperature that occur during exercise-induced $\dot{\mathrm{V}}_{\mathrm{O}_{2} \max }$, but not during cold-induced $\dot{\mathrm{V}}_{\mathrm{O}_{2} \text { max }}$. Finally, Gillooly \& Allen (2007) note that published scaling exponents for $\dot{\mathrm{V}}_{\mathrm{O}_{2} \max }$ based on data recorded under non-uniform conditions (Savage et al. 2004; Weibel et al. 2004; White \& Seymour 2005a) provide less support for their model than do the more uniform data on which their analysis is based.

Ambient temperature clearly affects rates of heat loss (Gates 1980), and therefore body and muscle temperatures of animals during strenuous exercise (Lindinger 1999; Gillooly $\&$ Allen 2007). From these observations, we hypothesized that, if the Gillooly \& Allen (2007) model is correct, massnormalized $\dot{\mathrm{V}}_{\mathrm{O}_{2} \max }$ will be positively related to the ambient temperature to which animals are exposed during measurements of $\dot{\mathrm{V}}_{\mathrm{O}_{2} \max }$. Moreover, by suggesting that differences in muscle temperature account for differences in aerobic scope (the difference between basal and maximal metabolic rate) between situations where $\dot{\mathrm{V}}_{\mathrm{O}_{2} \max }$ is exercise-, rather than cold-induced, Gillooly \& Allen (2007) implicitly make this prediction too.

In addition to the effects of ambient temperature, we also examined the effect of chronic thermal exposure on $\dot{\mathrm{V}}_{\mathrm{O}_{2} \max }$. Cold-acclimation resulting in facultative thermogenesis (via exposure to an extended duration of a cold stressor) often produces changes in muscle metabolism that alter skeletal muscle fibre composition (Ballantyne \& George 1978) and increase aerobic capacity, fatty acid oxidation (Dawson, Carey \& Van't Hof 1992), mitochondrial biogenesis (Wu et al. 1999) and exercise-induced $\dot{\mathrm{V}}_{\mathrm{O}_{2} \max }$ (Schaeffer et al. 2001, 2005; Schaeffer, Villarin \& Lindstedt 2003).

Thus, we hypothesized that $\dot{\mathrm{V}}_{\mathrm{O}_{2} \max }$ will be negatively related to acclimation temperature. The model on which Gillooly \& Allen (2007) based their predictions (Gillooly et al. 2001) can accommodate such a change. Gillooly et al. (2001) describe the effect of mass $(M, \mathrm{~g})$ and temperature $(T, \mathrm{~K})$ on metabolism $(B, \mathrm{~W})$ according to $B=b_{0} M^{3 / 4} e^{-E / k T}$, where $E$ represents an average activation energy for the rate-limiting enzymecatalyzed biochemical reactions of metabolism, $k$ is Boltzmann's constant $\left(8.62 \times 10^{-5} \mathrm{eV} \mathrm{K}^{-1}\right)$, and $b_{0}$ is a normalization constant (Gillooly et al. 2006). Thus, any acclimation effect will be reflected in $b_{0}$, the constant in the model, rather than $e^{-E / k T}$, the Boltzmann-Arrhenius factor (see also Clarke 2004, 2006; Gillooly et al. 2006). The hypothesis that $\dot{\mathrm{V}}_{\mathrm{O}_{2} \max }$ is negatively related to acclimation temperature can therefore neither support nor refute the model of Gillooly et al. (2001), but nevertheless represents a different view of the effect of temperature on $\dot{\mathrm{V}}_{\mathrm{O}_{2} \max }$ from that presented by Gillooly \& Allen (2007). Here, we test the above hypotheses using a phylogenetic generalized least-squares (PGLS) approach to examine the temperature dependence of $\dot{\mathrm{V}}_{\mathrm{O}_{2} \max }$ in mammals.

\section{Methods}

Data for $\dot{\mathrm{V}}_{\mathrm{O}_{2} \text { max }}$ of mammals were compiled from peer-reviewed literature (Table 1). $\dot{\mathrm{V}}_{\mathrm{O}_{2} \max }$ was measured during brief maximal exercise to exhaustion (Pasquis, Lacaisse \& Dejours 1970), or incremental treadmill exercise (Turner et al. 1995; Chappell et al. 2004; Chappell \& Hammond 2004; Kristan \& Hammond 2004; White, Matthews \& Seymour 2006a). Data obtained during brief maximal exercise (Pasquis et al. 1970) were comparable to measurements of the same species obtained during incremental exercise (Weibel et al. 2004). It is likely that exercise training would increase $\dot{\mathrm{V}}_{\mathrm{O}_{2} \max }$ obtained by both procedures (e.g. Butler \& Turner 1988; Turner et al. 1995), however, this is unlikely to compromise the present study because data for most species were obtained at more than one measurement temperature $\left(T_{\mathrm{m}},{ }^{\circ} \mathrm{C}\right)$ and acclimation temperature $\left(T_{\mathrm{a}},{ }^{\circ} \mathrm{C}\right)$ (Table 1). Thus, training status was not confounded with $T_{\mathrm{m}}$ or $T_{\mathrm{a}}$, and any training effect would be random with respect to $T_{\mathrm{m}}$ and $T_{\mathrm{a}}$.

Data for $T_{\mathrm{m}}$ and $T_{\mathrm{a}}$ were recorded in addition to $\dot{\mathrm{V}}_{\mathrm{O}_{2} \max }$ and body mass $(M)$. Only $\dot{\mathrm{V}}_{\mathrm{O}_{2} \max }$ data that were obtained at a known temperature were included in the analysis. Surprisingly, few studies report $T_{\mathrm{m}}$, even fewer maintain animals at a known temperature, and very few do both. The analysis is therefore limited to 34 measurements of six species of rodent ranging in mass from $20 \cdot 5$ to $939 \mathrm{~g}$.

Initially, data were analysed using PGLS ANCOVA. This analysis is necessary because metabolic rates for related species may not be statistically independent (e.g. Freckleton, Harvey \& Pagel 2002; Blomberg, Garland \& Ives 2003). Such non-independence violates the assumption of standard statistics that errors are uncorrelated, and may result in biased parameter estimates and increased type I error rates if it is not taken into account (Harvey \& Pagel 1991). The phylogeny used for analysis was compiled using the Tree of Life Web Project <http://tolweb.org/>, with branches proportional in length to the number of taxa descended from the node to which the branch leads. This is one model by which gradualistic evolutionary change may occur; this model produces an ultrametric phylogeny with short recent branches and longer ancient branches.

The PGLS approach was implemented in R using the Analysis of Phylogenetics and Evolution package and code written by R. P. Duncan. Full details of the approach are provided elsewhere (Halsey, Butler \& Blackburn 2006). Briefly, each statistical model was run by using each of two different assumptions about phylogenetic relatedness (phylogeny incorporated or conventional non-phylogenetic). A metric of the degree of phylogenetic correlation $(\lambda$, derived by Pagel 1999; Freckleton et al. 2002) was calculated for each of the three models of trait evolution considered (see below). $\lambda$ is a multiplier of the off-diagonal elements of the covariance matrix (i.e. those quantifying the degree of relatedness between species) and normally varies between 0 and 1 . If the covariance matrix is constructed assuming a Brownian-motion model of evolution, then $\lambda$ $=1$ retains that model; $\lambda=0$ specifies phylogenetic independence. Intermediate values of $\lambda$ specify models in which trait evolution is phylogenetically correlated, but to a lesser extent than expected under the Brownian-motion model. However, $\lambda=0$ for all three candidate models in the present study, indicating no phylogenetic signal in these models, and so we report the results of standard parametric analyses only. These analyses used mixed models with 
Table 1. Body mass, maximum aerobic metabolic rate $\left(\dot{\mathrm{V}}_{\mathrm{O}_{2} \max }\right)$, acclimation temperature $\left(T_{\mathrm{a}}\right)$ and measurement temperature $\left(T_{\mathrm{m}}\right)$ of rodents exercising at their aerobic capacity

\begin{tabular}{|c|c|c|c|c|c|}
\hline Species & Mass (g) & $\dot{\mathrm{V}}_{\mathrm{O}_{2} \max }\left(\mathrm{mL} \mathrm{min} \min ^{-1}\right)$ & $T_{\mathrm{a}}\left({ }^{\circ} \mathrm{C}\right)$ & $T_{\mathrm{m}}\left({ }^{\circ} \mathrm{C}\right)$ & References \\
\hline Mus musculus & 34 & $4 \cdot 0$ & 30 & -10 & Pasquis et al. (1970) \\
\hline Mus musculus & 35 & $5 \cdot 1$ & 30 & -3 & Pasquis et al. (1970) \\
\hline Mus musculus & 25 & $3 \cdot 5$ & 30 & 6 & Pasquis et al. (1970) \\
\hline Mus musculus & 26 & $3 \cdot 4$ & 30 & 30 & Pasquis et al. (1970) \\
\hline Mus musculus & 33 & $5 \cdot 7$ & 6 & -10 & Pasquis et al. (1970) \\
\hline Mus musculus & 31 & $4 \cdot 6$ & 6 & 6 & Pasquis et al. (1970) \\
\hline Mus musculus & $20 \cdot 5$ & $4 \cdot 0$ & 23 & 22 & Kristan \& Hammond (2004) \\
\hline Mus musculus & $20 \cdot 5$ & $4 \cdot 3$ & 5 & 22 & Kristan \& Hammond (2004) \\
\hline Rattus norvegicus & 371 & $22 \cdot 1$ & 30 & -10 & Pasquis et al. (1970) \\
\hline Rattus norvegicus & 346 & $25 \cdot 2$ & 30 & -3 & Pasquis et al. (1970) \\
\hline Rattus norvegicus & 286 & $25 \cdot 2$ & 30 & 6 & Pasquis et al. (1970) \\
\hline Rattus norvegicus & 223 & $17 \cdot 1$ & 30 & 30 & Pasquis et al. (1970) \\
\hline Rattus norvegicus & 375 & $29 \cdot 4$ & 6 & -10 & Pasquis et al. (1970) \\
\hline Rattus norvegicus & 376 & $33 \cdot 8$ & 6 & -3 & Pasquis et al. (1970) \\
\hline Rattus norvegicus & 292 & $26 \cdot 5$ & 6 & 6 & Pasquis et al. (1970) \\
\hline Cavia porcellus & 939 & $36 \cdot 9$ & 30 & -10 & Pasquis et al. (1970) \\
\hline Cavia porcellus & 868 & $56 \cdot 1$ & 30 & 6 & Pasquis et al. (1970) \\
\hline Cavia porcellus & 879 & $54 \cdot 4$ & 30 & 30 & Pasquis et al. (1970) \\
\hline Cavia porcellus & 843 & $56 \cdot 9$ & 6 & -10 & Pasquis et al. (1970) \\
\hline Cavia porcellus & 879 & $57 \cdot 8$ & 6 & -3 & Pasquis et al. (1970) \\
\hline Cavia porcellus & 849 & $52 \cdot 0$ & 6 & 6 & Pasquis et al. (1970) \\
\hline Cavia porcellus & 584 & $32 \cdot 6$ & 21 & 21 & Turner et al. (1995) \\
\hline Cavia porcellus & 528 & $38 \cdot 0$ & 6 & 21 & Turner et al. (1995) \\
\hline Cricetus auratus & 103 & $9 \cdot 4$ & 29 & 29 & Pasquis et al. (1970) \\
\hline Cricetus auratus & 113 & $11 \cdot 2$ & 26 & 26 & Pasquis et al. (1970) \\
\hline Cricetus auratus & 101 & $11 \cdot 9$ & $12 \cdot 5$ & 6 & Pasquis et al. (1970) \\
\hline Peromyscus maniculatus & $23 \cdot 4$ & $4 \cdot 7$ & 5 & 20 & Chappell \& Hammond (2004) \\
\hline Peromyscus maniculatus & $24 \cdot 4$ & $4 \cdot 7$ & 21 & 20 & Chappell \& Hammond (2004) \\
\hline Peromyscus maniculatus & $23 \cdot 4$ & $5 \cdot 1$ & 5 & 0 & Chappell \& Hammond (2004) \\
\hline Peromyscus maniculatus & $24 \cdot 4$ & $4 \cdot 7$ & 21 & 0 & Chappell \& Hammond (2004) \\
\hline Peromyscus maniculatus & $23 \cdot 4$ & $4 \cdot 7$ & 5 & -16 & Chappell \& Hammond (2004) \\
\hline Peromyscus maniculatus & $24 \cdot 4$ & $3 \cdot 2$ & 21 & -16 & Chappell \& Hammond (2004) \\
\hline Peromyscus maniculatus & $22 \cdot 2$ & $4 \cdot 2$ & 25 & $23 \cdot 5$ & Chappell et al. (2004) \\
\hline Notomys alexis & 33 & $4 \cdot 2$ & 24 & $20 \cdot 6$ & White et al. (2006a) \\
\hline
\end{tabular}

species as a random effect, implemented in $\mathrm{R}$ via the lme function with ML option, to account for potential pseudoreplication arising from multiple measurements from the same species. Means are presented \pm SEM, and $\alpha$ was set at $0 \cdot 05$.

The effects of $\log (M), T_{\mathrm{a}}$ and $T_{\mathrm{m}}$ on $\log \left(\dot{\mathrm{V}}_{\mathrm{O}_{2} \max }\right)$ were examined. Gillooly \& Allen's (2007) hypothesis was supported if the effect of $T_{\mathrm{m}}$ was positive and significant. Three statistical models were compared on the basis of AIC (Burnham \& Anderson 2001): $\log \left(\dot{\mathrm{V}}_{\mathrm{O}_{2} \text { max }}\right)=$ $\log (M)+T_{\mathrm{a}}, \log \left(\dot{\mathrm{V}}_{\mathrm{O}_{2} \max }\right)=\log (M)+T_{\mathrm{m}}$, and $\log \left(\dot{\mathrm{V}}_{\mathrm{O}_{2} \max }\right)=\log (M)+$ $T_{\mathrm{m}}+T_{\mathrm{a}}$. The best of the three models was that with the lowest AIC. The probability that any given model is actually the best fit out of those tested was measured by its Akaike weight $\left(w_{i}\right)$, the relativelikelihood of the model (Burnham \& Anderson 2001).

\section{Results}

The best model, given the data, described $\log \left(\dot{\mathrm{V}}_{\mathrm{O}_{2} \max }\right)$ in terms of $\log (M)$ and $T_{\text {a }}$ (Table 2, Fig. 1). The statistical model including $\log (M)$ and $T_{\mathrm{a}}$ is 9100 times more likely to provide the best fit to the data than the model including $\log (M)$ and $T_{\mathrm{m}}$ (Table 3). Controlling for $M, T_{\mathrm{m}}$ was not significantly correlated with $\dot{\mathrm{V}}_{\mathrm{O}_{2} \max }$, (Table 4), despite spanning a range from $-16^{\circ} \mathrm{C}$ to $30^{\circ} \mathrm{C}$. The probability that $\log \left(\dot{\mathrm{V}}_{\mathrm{O}_{2} \text { max }}\right)$ is best described in terms of either $\log (M)$ and $T_{\mathrm{a}}$, or $\log (M), T_{\mathrm{m}}$ and $T_{\mathrm{a}}$ is 0.9999 , whereas the probability that $\log \left(\dot{\mathrm{V}}_{\mathrm{O}_{2} \max }\right)$ is best

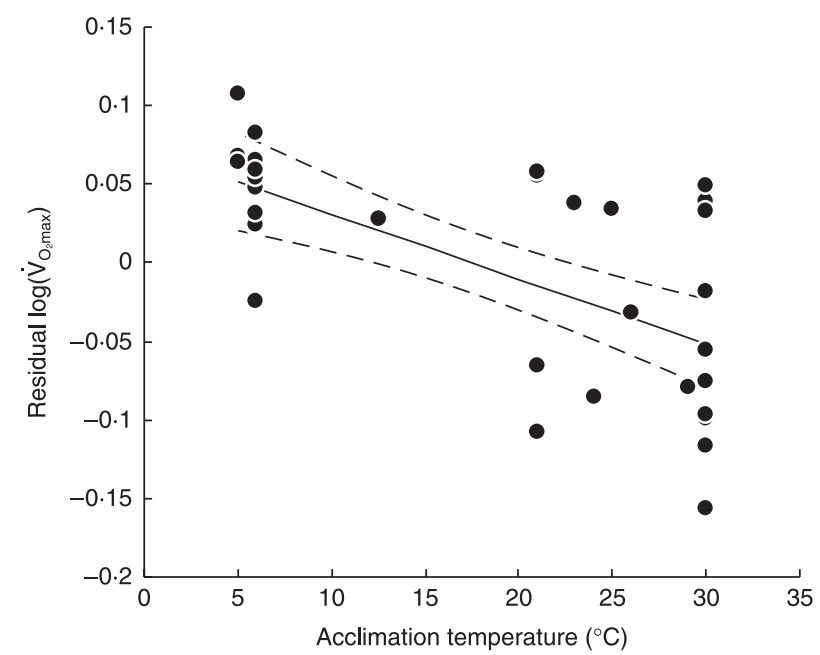

Fig. 1. Relationship between residual $\dot{\mathrm{V}}_{\mathrm{O}_{2} \max }\left(=\right.$ measured $\dot{\mathrm{V}}_{\mathrm{O}_{2} \max }-$ $\dot{\mathrm{V}}_{\mathrm{O}_{2} \max }$ predicted by body mass) and acclimation temperature.

described in terms of $\log (M)$ and $T_{\mathrm{m}}$ is vanishingly small $(<0 \cdot 0001)$ (Table 3). The model including mass, $T_{\mathrm{a}}$ and $T_{\mathrm{m}}$ $\left(w_{\mathrm{i}}=0 \cdot 44\right.$, Table 3$)$ is only a slightly worse fit to the data than the model with just mass and $T_{\mathrm{a}}\left(w_{i}=0 \cdot 56\right.$, Table 3$)$, but this 
Table 2. AIC values, Akaike weights $\left(w_{\mathrm{i}}\right.$, the probability that the model is the correct one of those tested) and values of $\lambda$ (a measure of phylogenetic correlation) for the six statistical and evolutionary models ( $\dot{\mathrm{V}}_{\mathrm{O}_{2} \max }$, exercise-induced maximum metabolic rate; $M$, body mass; $T_{\mathrm{a}}$, acclimation temperature; $T_{\mathrm{m}}$, measurement temperature; star, conventional across species analysis; proportional, GLS model incorporating information on phylogenetic relatedness, with branches proportional in length to the number of taxa descended from the node to which the branch leads)

\begin{tabular}{lllll}
\hline Model & Phylogeny & $\lambda$ & AIC & $w_{\mathrm{i}}$ \\
\hline $\log \left(\dot{\mathrm{V}}_{\mathrm{O}_{2} \max }\right) \sim \log (M)+T_{\mathrm{a}}$ & Star & - & $-96 \cdot 04$ & $0 \cdot 41$ \\
$\log \left(\dot{\mathrm{V}}_{\mathrm{O}_{2} \max }\right) \sim \log (M)+T_{\mathrm{a}}$ & Proportional & 0 & $-94 \cdot 04$ & $0 \cdot 15$ \\
$\log \left(\dot{\mathrm{V}}_{\mathrm{O}^{\max }}\right) \sim \log (M)+T_{\mathrm{m}}$ & Star & - & $-77 \cdot 8$ & $0 \cdot 00005$ \\
$\log \left(\dot{\mathrm{V}}_{\mathrm{O}_{2} \max } \sim \log (M)+T_{\mathrm{m}}\right.$ & Proportional & 0 & $-75 \cdot 8$ & $0 \cdot 00002$ \\
$\log \left(\dot{\mathrm{V}}_{\mathrm{O}_{2} \max }\right) \sim \log (M)+T_{\mathrm{a}}+T_{\mathrm{m}}$ & Star & - & $-95 \cdot 52$ & $0 \cdot 32$ \\
$\log \left(\dot{\mathrm{V}}_{\mathrm{O}_{2} \max }\right) \sim \log (M)+T_{\mathrm{a}}+T_{\mathrm{m}}$ & Proportional & 0 & $-93 \cdot 52$ & $0 \cdot 12$ \\
\hline
\end{tabular}

Table 3. Akaike weights $\left(w_{\mathrm{i}}\right.$, the probability that the model is the correct one of those tested) for the three statistical models listed in Table 2, summed over the two evolutionary models $\left(\dot{\mathrm{V}}_{\mathrm{O}_{2} \max }\right.$, exerciseinduced maximum metabolic rate; $M$, body mass; $T_{\mathrm{a}}$, acclimation temperature; $T_{\mathrm{m}}$, measurement temperature)

\begin{tabular}{ll}
\hline Model & $w_{i}$ \\
\hline $\log \left(\dot{\mathrm{V}}_{\mathrm{O}_{\max }}\right) \sim \log (M)+T_{\mathrm{a}}$ & $0 \cdot 56$ \\
$\log \left(\dot{\mathrm{V}}_{\mathrm{O}_{2} \max } \sim \log (M)+T_{\mathrm{m}}\right.$ & $0 \cdot 00006$ \\
$\log \left(\dot{\mathrm{V}}_{\mathrm{O}_{2} \max }\right) \sim \log (M)+T_{\mathrm{a}}+T_{\mathrm{m}}$ & $0 \cdot 44$ \\
\hline
\end{tabular}

is largely because of the presence of mass and $T_{\mathrm{a}}$ in both models; $T_{\mathrm{m}}$ does not explain significant variance in $\log \left(\dot{\mathrm{V}}_{\mathrm{O}_{2} \max }\right)$ in this full model (Table 4).

\section{Discussion}

Our data show clearly that measurement temperature $\left(T_{\mathrm{m}}\right)$ is not related to $\dot{\mathrm{V}}_{\mathrm{O}_{2} \max }$, even though $\dot{\mathrm{V}}_{\mathrm{O}_{2} \max }$ was measured across a wide range of temperatures $\left(-16^{\circ} \mathrm{C}\right.$ to $\left.30^{\circ} \mathrm{C}\right)$. Ambient temperature had a significant effect on rates of muscle warming during strenuous exercise in at least humans and horses (Lindinger 1999), and it can probably be assumed that the $46{ }^{\circ} \mathrm{C}$ range of temperatures will have influenced muscle temperature during exercise in the smaller species considered in the present study. It is, therefore, also clear that $\dot{\mathrm{V}}_{\mathrm{O}_{2} \max }$ is not elevated as a result of high muscle temperature. However, we did find a significant effect of acclimation temperature on $\dot{\mathrm{V}}_{\mathrm{O}_{2} \max }$ in rodents (Fig. 1), as was previously reported for goats and opossums (Schaeffer et al. 2001, 2003), but not for all species that have been examined to date (Chappell \& Hammond 2004). Thus, we conclude that, although individual species may differ in the effect of acclimation temperature on $\dot{\mathrm{V}}_{\mathrm{O}_{2} \text { max }}$, there is a negative relationship between acclimation temperature and $\dot{\mathrm{V}}_{\mathrm{O}_{2} \text { max }}$. The effect of acclimation is far from trivial: mean $\dot{\mathrm{V}}_{\mathrm{O}_{2} \text { max }}$ at a $T_{\mathrm{a}}$ of $5{ }^{\circ} \mathrm{C}$ is $27 \%$ higher than mean $\dot{\mathrm{V}}_{\mathrm{O}_{2} \max }$ at $30{ }^{\circ} \mathrm{C}$, which exceeds the $12 \%-20 \%$ increase in $\dot{\mathrm{V}}_{\mathrm{O}_{2} \max }$ associated with artificial selection for voluntary running in mice (Swallow et al. 1998; Rezende et al. 2006). The increase in $\dot{\mathrm{V}}_{\mathrm{O}_{2} \text { max }}$ between $30{ }^{\circ} \mathrm{C}$ and $5{ }^{\circ} \mathrm{C}$ is similar to the $23 \%-27 \%$ increase in $\dot{\mathrm{V}}_{\mathrm{O}_{2} \max }$ elicited by exercise training in ducks and guinea pigs (Butler \& Turner 1988; Turner et al. 1995), and approaches the difference of around $40 \%$ observed between elite human endurance athletes (runners and orienteers) and healthy untrained non-athletes (Marti \& Howald 1990 ) and the difference of $50 \%$ observed between rats selectively bred for high and low endurance capacity (Gonzalez et al. 2006).

Surprisingly, we found a scaling exponent for $\dot{\mathrm{V}}_{\mathrm{O}_{2} \max }$ of $0 \cdot 70 \pm 0 \cdot 01$. This is lower than that found in other studies, which generally report a scaling exponent $>0.75$ (Savage et al. 2004; Weibel et al. 2004), but is similar to that reported for cold-induced $\dot{\mathrm{V}}_{\mathrm{O}_{2} \text { max }}$ measured in a $\mathrm{He}-\mathrm{O}_{2}$ atmosphere (Bozinovic \& Rosenmann 1989; Bozinovic 1992; Rezende, Bozinovic \& Garland 2004; White \& Seymour 2005a). One may be tempted to use this low scaling exponent as evidence against the Gillooly \& Allen (2007) model, which predicts that muscle temperatures rise more in small species than in large ones if $b<0 \cdot 75$. However, we caution against such interpretation, because our sample size (34 measurements of only six species) and body mass range (20.5-939 g, 1.7 orders of magnitude) is probably too small to estimate the scaling exponent reliably (White $\&$ Seymour 2005b). We also combine intra- and interspecific data, which may lower the scaling exponent. Intraspecific exponents of BMR, for example, are typically lower than interspecific exponents (Glazier 2005). Recent analyses of interspecific compilations, including more species spanning a larger mass range, provide unanimous support for a $\dot{\mathrm{V}}_{\mathrm{O}_{2} \max }$ scaling exponent $>0.75$ (Savage et al. 2004; Weibel et al. 2004; Weibel \& Hoppeler 2005; White \& Seymour 2005a).

Given the likely association of muscle temperature during strenuous exercise and $T_{\mathrm{m}}$, together with the lack of association between $T_{\mathrm{m}}$ and $\dot{\mathrm{V}}_{\mathrm{O}_{2} \max }$, it seems unlikely that the elevated muscle temperatures observed in large species are responsible

Table 4. Parameter estimates for the three non-phylogenetic models for exercise-induced maximum metabolic rate listed in Table 2 ( $M$, body mass; $T_{\mathrm{a}}$, acclimation temperature; $T_{\mathrm{m}}$, measurement temperature)

\begin{tabular}{lccc}
\hline & $\log (M)+T_{\mathrm{a}}\left(w_{i}=0 \cdot 41\right)$ & $\log (M)+T_{\mathrm{m}}\left(w_{i}=0 \cdot 00005\right)$ & $\log (M)+T_{\mathrm{a}}+T_{\mathrm{m}}\left(w_{i}=0 \cdot 32\right)$ \\
\hline Intercept & $-0 \cdot 28 \pm 0 \cdot 04^{*}$ & $-0 \cdot 35 \pm 0 \cdot 04^{*}$ & $-0 \cdot 28 \pm 0 \cdot 04^{*}$ \\
$\log (M)$ & $0 \cdot 70 \pm 0 \cdot 01^{*}$ & $0 \cdot 70 \pm 0 \cdot 02^{*}$ & $0 \cdot 70 \pm 0 \cdot 01^{*}$ \\
$T_{\mathrm{a}}$ & $-0 \cdot 0041 \pm 0 \cdot 0008^{*}$ & & $-0 \cdot 0043 \pm 0 \cdot 0009^{*}$ \\
$T_{\mathrm{m}}$ & & $-0 \cdot 000048 \pm 0 \cdot 000841^{\mathrm{NS}}$ & $0 \cdot 00076 \pm 0 \cdot 00066^{\mathrm{NS}}$ \\
\hline
\end{tabular}

$* P<0 \cdot 001 ;{ }^{\mathrm{NS}}$ not significant. 
for the elevation of the scaling exponent for $\dot{\mathrm{V}}_{\mathrm{O}_{2} \max }$ above the value of 0.75 predicted by recent models (West et al. 1997; Banavar et al. 1999). Below, we address the effect of acclimation temperature on $\dot{\mathrm{V}}_{\mathrm{O}_{2} \max }$ and then discuss three other lines of evidence which suggest that elevated muscle temperatures do not elevate $\dot{\mathrm{V}}_{\mathrm{O}_{2} \max }$. First, we discuss the transport of oxygen from air to muscle mitochondria, and show that the respiration rate of mitochondria probably cannot increase beyond that observed at $\dot{\mathrm{V}}_{\mathrm{O}_{2} \max }$. We then demonstrate that body temperature and $\dot{\mathrm{V}}_{\mathrm{O}_{2}}$ are temporally uncoupled in animals exercising at $\dot{\mathrm{V}}_{\mathrm{O}_{2} \max }$, that animals can attain $\dot{\mathrm{V}}_{\mathrm{O}_{2} \max }$ before body temperature has risen appreciably, and that body temperature rises continually during strenuous exercise, whereas $\dot{\mathrm{V}}_{\mathrm{O}_{2} \max }$ does not. Finally, we examine the effect of temperature on the exercise metabolism of ectotherms, and show that there is no ubiquitous link between body temperature and $\dot{\mathrm{V}}_{\mathrm{O}_{2} \max }$, even in species that operate over a wide range of body temperatures. We conclude that elevated muscle temperatures do not explain the $>0.75$ power scaling of $\dot{\mathrm{V}}_{\mathrm{O}_{2} \max }$.

\section{THE EFFECT OF ACCLIMATION TEMPERATURE ON $\dot{\mathrm{V}}_{\mathrm{O}_{2} \max }$}

The effect of acclimation temperature on $\dot{\mathrm{V}}_{\mathrm{O}_{2} \max }$ arises because thermogenesis associated with prolonged cold exposure acts as a form of aerobic training, rather than as a consequence of a direct effect on muscle temperature (Schaeffer et al. 2001, 2003). Shivering is the primary mechanism utilized in response to a cold stressor, but there is increasing support for the role of muscle-mediated non-shivering thermogenesis in skeletal muscle of placental mammals (Dubois-Ferrière \& Chinet 1981), birds (Duchamp \& Barre 1993) and marsupial mammals (Rose et al. 1999; Kabat, Rose \& West 2003, 2004, 2007). Longterm cold exposure has been reported to increase muscle oxidative capacity in many species. Furthermore, as the ambient temperature drops below thermoneutrality, there is a linear increase in heat production with decreasing ambient temperature, which results in increases in $\dot{\mathrm{V}}_{\mathrm{O}_{2} \max }$ (Block 1994; Schaeffer et al. 2005).

Acclimation to cold acts as an effective stimulus of muscle plasticity, modifying muscle function and eliciting a shift in skeletal muscle fibres from fast-to-slow twitch, thereby enhancing metabolic heat production (Schaeffer et al. 2003, 2005). Such cold-acclimation resulting from chronic musclemediated thermogenesis (both shivering and non-shivering) can cause an increase in $\dot{\mathrm{V}}_{\mathrm{O}_{2} \max }$ that equals or exceeds that typical of endurance training (Schaeffer et al. 2001, 2005). This 'acclimation training effect' often increases aerobic capacity, fatty acid oxidation (Dawson et al. 1992), mitochondrial biogenesis (Wu et al. 1999) and alters fibre composition (Ballantyne \& George 1978).

\section{OXYGEN TRANSPORT FROM AIR TO MITOCHONDRIA}

According to the evolutionary hypothesis of symmorphosis, the elements of the gas-transport system in animals should be matched to the maximal aerobic demand of the system and no more (Weibel 2000). While this hypothesis has attracted vigorous criticism (Garland \& Huey 1987; Dudley \& Gans 1991; Garland 1998), it nevertheless represents a suitable null hypothesis from which to examine the transport of oxygen from the atmosphere to mitochondria, via the oxygen-transport cascade (Diamond 1992). Symmorphosis proposes that animals are designed reasonably, and that the functional capacities of the oxygen transport cascade are matched such that no step in the cascade shows excess capacity (Weibel, Taylor \& Hoppeler 1991; Weibel 2000). Thus, the rate at which mitochondria can use oxygen should be matched to the rate at which oxygen can be delivered to mitochondria (Lindstedt \& Conley 2001; Weibel et al. 2004).

The capacity matching of the steps in the oxygen cascade is demonstrated by the observation that substantial increases in oxygen delivery elicited by induced erythrocythemia or acute hyperoxic exposure during exercise result in only modest increases in $\dot{\mathrm{V}}_{\mathrm{O}_{2} \max }$ (Spriet et al. 1986; Jones 1998a,b; Richardson et al. 1999). This suggests that enhanced oxygen delivery exceeds the capacity of the oxygen sink (mitochondria) in the exercising muscles (Lindstedt \& Conley 2001), or that $\dot{\mathrm{V}}_{\mathrm{O}_{2} \max }$ is limited by all steps of the oxygen cascade such that an increased mitochondrial demand for oxygen cannot be met (Jones 1998a, b). In vitro experiments show that the maximal rate of oxygen consumption of mitochondria is $5.8 \mathrm{~mL}$ $\mathrm{O}_{2} \mathrm{~cm}^{-3} \min ^{-1}$ (Schwerzmann et al. 1989), a value similar to the estimated in vivo rate of oxygen consumption of mitochondria in animals exercising at $\dot{\mathrm{V}}_{\mathrm{O}_{2} \max }\left(5 \cdot 2 \pm 0 \cdot 4[\mathrm{SE}] \mathrm{mL} \mathrm{O}_{2} \mathrm{~cm}^{-3} \mathrm{~min}^{-1}\right.$; range $3 \cdot 2-8 \cdot 9 \mathrm{~mL} \mathrm{~min}^{-1}$ ) (Weibel et al. 2004). Thus, skeletal muscle mitochondria in mammals exercising at $\dot{\mathrm{V}}_{\mathrm{O}_{2} \max }$ respire close to their maximum capacities in vivo (Taylor 1987; Schwerzmann et al. 1989; Suarez 1996).

Regardless of whether the oxygen cascade lacks capacity to deliver increased oxygen to mitochondria, or if mitochondria lack capacity to increase oxygen consumption beyond that observed at $\dot{\mathrm{V}}_{\mathrm{O}_{2} \max }$, the rate of oxygen delivery from air to muscle mitochondria cannot be increased beyond the rate observed in animals exercising at $\dot{\mathrm{V}}_{\mathrm{O}_{2} \max }$. Thus, increases in muscle temperature cannot result in increases in $\dot{\mathrm{V}}_{\mathrm{O}_{2} \max }$.

\section{TEMPORAL UNCOUPLING OF BODY TEMPERATURE AND $\dot{\mathrm{V}}_{\mathrm{O}_{2} \max }$}

The time course of changes in $\dot{\mathrm{V}}_{\mathrm{O}_{2}}$ and muscle temperature during maximal exercise also fails to support the hypothesis that elevated temperatures influence $\dot{\mathrm{V}}_{\mathrm{O}_{2} \max } \cdot \dot{\mathrm{V}}_{\mathrm{O}_{2}}$ kinetics in the horse, for example, are extremely rapid (Evans \& Rose 1988; Langsetmo et al. 1997), but changes in temperature are slower (Jones et al. 1989). At 30 and $60 \mathrm{~s}$ after commencement of exercise at a work rate equivalent to $100 \%$ of $\dot{\mathrm{V}}_{\mathrm{O}_{2} \max }$, mean $\dot{\mathrm{V}}_{\mathrm{O}_{2}}$ of the horse was equal to $82.5 \%$ and $94.6 \%$ of $\dot{\mathrm{V}}_{\mathrm{O}_{2} \max }$, respectively (Evans \& Rose 1988). Muscle temperature, on the other hand, increased continually from $c .38^{\circ} \mathrm{C}$ to $42 \cdot 5^{\circ} \mathrm{C}$ throughout 6 min of exercise at $98 \%$ of $\dot{\mathrm{V}}_{\mathrm{O}_{2} \max }$, and rose only $1 \cdot 3{ }^{\circ} \mathrm{C}$ during the first $60 \mathrm{~s}$ (Jones et al. 1989). Furthermore, the stable plateau values of $\dot{\mathrm{V}}_{\mathrm{O}_{2}}$ at high speed observed during graded exercise (e.g. Seeherman et al. 1981) 
demonstrates that $\dot{\mathrm{V}}_{\mathrm{O}_{2}}$ does not increase beyond $\dot{\mathrm{V}}_{\mathrm{O}_{2} \max }$, despite the continual increase in temperature. Rather than increasing $\dot{\mathrm{V}}_{\mathrm{O}_{2} \max }$, rising body temperatures actually limit the duration of high intensity exercise (Fuller, Carter \& Mitchell 1998; González-Alonso et al. 1999), and $\dot{\mathrm{V}}_{\mathrm{O}_{2} \max }$ is reduced by exercise-induced or passive preheating (Arngrímsson et al. 2004). Similarly, in humans, cooling does not alter $\dot{V}_{\mathrm{O}_{2} \max }$ in the direction predicted by the model of Gillooly \& Allen (2007). Rather, convective cooling results in an increase in $\dot{\mathrm{V}}_{\mathrm{O}_{2} \max }$ rather than a decrease (Wingo \& Cureton 2006).

\section{THE EFFECT OF TEMPERATURE ON $\dot{V}_{\mathrm{O}_{2} \max }$ OF ECTOTHERMS}

The different scaling of exercise and resting metabolic rate is taxonomically widespread (White et al. 2007), extending to amphibians (Walton 1993), fish (Killen et al. 2007) and arthropods (terrestrial arthropods and insects show $>0.75$ scaling of maximum performance gas exchange variables that are closely related to $\dot{\mathrm{V}}_{\mathrm{O}_{2} \text { max }}$; see review in Chown \& Nicolson 2004). Ideally, any attempt to explain the non-quarter-power scaling of $\dot{\mathrm{V}}_{\mathrm{O}_{2} \text { max }}$ should hold across a broad range of taxa (note, however, that Gillooly \& Allen (2007) explicitly limit their model to mammals). In insects, $\dot{\mathrm{V}}_{\mathrm{O}_{2}}$ during hovering flight scales with $M^{0.82}$ (Bartholomew \& Casey 1978), and the 70-80 fold increase in $\dot{\mathrm{V}}_{\mathrm{O}_{2}}$ or $\dot{\mathrm{V}}_{\mathrm{CO}_{2}}$ shown by many species is accompanied by $10{ }^{\circ} \mathrm{C}$ to $15^{\circ} \mathrm{C}$ changes in body temperature (Chown \& Nicolson 2004). Thoracic temperature during hovering flight is related to ambient temperature (Heinrich 1993; p. 32, fig. 1·11), but $\dot{\mathrm{V}}_{\mathrm{O}_{2}}$ is not (Heinrich 1993; p. 33, fig. 1·12). Thus, temperature also fails to account for the $>0.75$ power scaling of $\dot{\mathrm{V}}_{\mathrm{O}_{2}}$ during hovering flight in insects, despite the substantial variation in flight muscle temperature observed in these species.

However, $\dot{\mathrm{V}}_{\mathrm{O}_{\text {, } \max }}$ does increase with temperature in fish and reptiles. $\dot{\mathrm{V}}_{\mathrm{O}_{2}}$ at maximum sustainable swimming speed is positively related to body temperature in fish (Duthie 1982; Clark et al. 2005), but this may not represent $\dot{\mathrm{V}}_{\mathrm{O}_{2} \max }$ (Reidy et al. 1995). Therefore, an examination of the effect of temperature on post-exhaustion $\dot{\mathrm{V}}_{\mathrm{O}_{2}}$ is required to determine if temperature influences $\dot{\mathrm{V}}_{\mathrm{O}_{2} \max }$ of fish. In reptiles, $\dot{\mathrm{V}}_{\mathrm{O}_{2} \max }$ is positively related to temperature at low temperatures, but independent of temperature at high temperatures (Bennett 1978, 1982), except in species with high aerobic capacity (Bennett 1972; Clark et al. 2004). Nevertheless, the relationship between temperature and $\dot{\mathrm{V}}_{\mathrm{O}_{2} \max }$ observed in these species cannot account for the different scaling exponents observed for exercise and resting metabolic rate, because these are obtained for animals at equivalent ambient temperatures (e.g. Walton 1993; Killen et al. 2007).

\section{Conclusion}

In attempting to explain the $>0 \cdot 75$-power scaling of $\dot{\mathrm{V}}_{\mathrm{O}_{2} \max }$ in terms of changes in muscle temperature, a major simplification of the Gillooly \& Allen (2007) model is that it fails to account for physiological mechanisms and geometric con- straints of body size and morphology that influence heating in exercising animals. The extent to which muscle temperature increases during strenuous exercise will be determined by a balance between the rate at which metabolic heat is produced by muscular work (i.e. the sum of aerobic and anaerobic metabolic rate), and the rate at which heat is dissipated, which is constrained by geometry and influenced by physiological mechanisms of thermoregulation (e.g. blood-flow shunting between organs and skeletal muscle, counter-current heat exchange). At $\dot{\mathrm{V}}_{\mathrm{O}_{2} \max }$, large species have higher muscle temperatures than small species because they have a greater aerobic scope and greater problems dissipating heat. Large species do not have high aerobic scopes because they have higher muscle temperatures during strenuous exercise. The difference between the scaling exponents of $\dot{\mathrm{V}}_{\mathrm{O}_{2} \max }$ and standard or basal metabolic rate cannot be explained solely on the basis of variation in muscle temperature. Instead, the scaling of $\dot{\mathrm{V}}_{\mathrm{O}_{2} \max }$ in mammals arises because the majority of oxygen is consumed by skeletal muscles at $\dot{\mathrm{V}}_{\mathrm{O}_{2} \max }$ (Taylor 1987; Weibel et al. 2004). $\dot{\mathrm{V}}_{\mathrm{O}_{2} \max }$ is therefore tightly linked to the aerobic capacity of the locomotor musculature: the total volume of muscle mitochondria and total muscle capillary volume scale with nearly identical exponents, both of which are nearly identical to the scaling exponent of $\dot{\mathrm{V}}_{\mathrm{O}_{2} \max }$, and $>0.75$ (Weibel et al. 2004).

\section{Acknowledgements}

We thank two anonymous reviewers and the associate editor, who provided comments that improved an earlier version of this manuscript. CRW was supported by Natural Environment Research Council grant NER/A/2003/00542 to G. R. Martin, PJB, and A. J. Woakes. JST and SLC are supported by the DST-NRF Centre of Excellence for Invasion Biology.

\section{References}

Arngrímsson, S.A., Petitt, D.S., Borrani, F., Skinner, K.A. \& Cureton, K.J. (2004) Hyperthermia and maximal oxygen uptake in men and women. European Journal of Applied Physiology, 92, 524-532.

Ballantyne, J.S. \& George, J.C. (1978) Ultrastructural and histological analysis of effects of cold acclimation on vertebrate skeletal muscle. Journal of Thermal Biology, 3, 109-116.

Banavar, J.R., Maritan, A. \& Rinaldo, A. (1999) Size and form in efficient transportation networks. Nature, 399, 130-131.

Bartholomew, G.A. \& Casey, T.M. (1978) Oxygen consumption of moths during rest, pre-flight warm-up, and flight in relation to body size and wing morphology. Journal of Experimental Biology, 76, 11-25.

Bennett, A.F. (1972) The effect of activity on oxygen consumption, oxygen debt, and heart rate in the lizards Varanus gouldii and Sauromalus hispidus. Journal of Comparative Physiology, 79, 259-280.

Bennett, A.F. (1978) Activity metabolism of the lower vertebrates. Annual Review of Physiology, 400, 447-469.

Bennett, A.F. (1982) Energetics of activity in reptiles. Biology of the Reptilia (eds C. Gans \& F.H. Pough). Academic Press, New York.

Block, B.A. (1994) Thermogenesis in muscle. Annual Review of Physiology, 56, 535-577.

Blomberg, S.P., Garland, T. Jr. \& Ives, A.R. (2003) Testing for phylogenetic signal in comparative data: behavioral traits are more labile. Evolution 57, 717-745.

Bokma, F. (2004) Evidence against universal metabolic allometry. Functional Ecology, 18, 184-187.

Bozinovic, F. (1992) Scaling of basal and maximum metabolic rate in rodents and the aerobic capacity model for the evolution of endothermy. Physiological Zoology, 65, 921-932. 
Bozinovic, F. \& Rosenmann, M. (1989) Maximum metabolic rate of rodents physiological and ecological consequences on distributional limits. Functional Ecology, 3, 173-181.

Burnham, K.P. \& Anderson, D.R. (2001) Kullback-Leibler information as a basis for strong inference in ecological studies. Wildlife Research, 28, 111119.

Butler, P.J. \& Turner, D.L. (1988) Effect of training on maximal oxygen uptake and aerobic capacity of locomotory muscles in tufted ducks, Aythya fuligula. Journal of Physiology, 401, 347-359.

Chappell, M.A. \& Hammond, K.A. (2004) Maximal aerobic performance of deer mice in combined cold and exercise challenges. Journal of Comparative Physiology B - Biochemical Systemic and Environmental Physiology, 174, 41-48.

Chappell, M.A., Garland, T. Jr., Rezende, E.L. \& Gomes, F.R. (2004) Voluntary running in deer mice: speed, distance, energy costs and temperature effects. Journal of Experimental Biology, 207, 3839-3854.

Chown, S.L. \& Nicolson, S.W. (2004) Insect Physiological Ecology: Mechanisms and Patterns. Oxford University Press, New York.

Chown, S.L., Marais, E., Terblanche, J.S., Klok, C.J., Lighton, J.R.B. \& Blackburn, T.M. (2007) Scaling of insect metabolic rate is inconsistent with the nutrient supply network model. Functional Ecology, 21, 282-290.

Clark, T.D., Ryan, T., Ingram, B.A., Woakes, A.J., Butler, P.J. \& Frappell, P.B. (2005) Factorial aerobic scope is independent of temperature and primarily modulated by heart rate in exercising Murray cod (Maccullochella peelii peelii). Physiological and Biochemical Zoology, 78, 347-355.

Clark, T.D., Wang, T., Butler, P.J. \& Frappell, P.B. (2004) Factorial scopes of cardio-metabolic variables remain constant with changes in body temperature in the varanid lizard, Varanus rosenbergi. American Journal of Physiology Regulatory Integrative and Comparative Physiology, 288, R992R997.

Clarke, A. (2004) Is there a universal temperature dependence of metabolism? Functional Ecology, 18, 252-256.

Clarke, A. (2006) Temperature and the metabolic theory of ecology. Functional Ecology, 20, 405-412.

Dawson, W.R., Carey, C. \& Van’t Hof, T.J. (1992) Metabolic aspects of shivering thermogenesis in passerines during winter. Ornis Scandinavica, 23, 381-387.

Diamond, J.M. (1992) The red flag of optimality. Nature, 355, 204-206.

Dubois-Ferrière, R. \& Chinet, A.E. (1981) Contribution of skeletal muscle to the regulatory non-shivering thermogenesis in small mammals. Pflugers Archive - European Journal of Physiology, 390, 224-229.

Duchamp, C. \& Barre, H. (1993) Skeletal muscle as the major site of nonshivering thermogenesis in cold-acclimated ducklings. American Journal of Physiology, 265, R1076-R1083.

Dudley, R. \& Gans, C. (1991) A critique of symmorphosis and optimality models in physiology. Physiological Zoology, 64, 627-637.

Duthie, G.G. (1982) The respiratory metabolism of temperature-adapted flatfish at rest and during swimming activity and the use of anaerobic metabolism at moderate swimming speeds. Journal of Experimental Biology, 97, 359-373.

Evans, D.L. \& Rose, R.J. (1988) Dynamics of cardiorespiratory function in standardbred horses during different intensities of constant-load exercise. Journal of Comparative Physiology B, 157, 791-799.

Farrell-Gray, C.C. \& Gotelli, N.J. (2005) Allometric exponents support a 3/4power scaling law. Ecology, 86, 2083-2087.

Freckleton, R.P., Harvey, P.H. \& Pagel, M. (2002) Phylogenetic analysis and comparative data: A test and review of evidence. American Naturalist, 160, $712-726$.

Fuller, A., Carter, R.N. \& Mitchell, D. (1998) Brain and abdominal temperatures at fatigue in rats exercising in the heat. Journal of Applied Physiology, 84, 877-883.

Garland, T. Jr. (1998) Conceptual and methodological issues in testing the predictions of symmorphosis. Principles of Animal Design: the Optimization and Symmorphosis Debate (eds E.R. Weibel, C.R. Taylor \& L. Bolis), pp. 40 47. Cambridge University Press, Cambridge.

Garland, T. Jr. \& Huey, R.B. (1987) Testing symmorphosis: does structure match functional requirements? Evolution, 41, 1404-1409.

Gates, D.M. (1980) Biophysical Ecology. Springer-Verlag, New York.

Gillooly, J.F. \& Allen, A.P. (2007) Changes in body temperature influence the scaling of $\dot{\mathrm{V}}_{\mathrm{O}_{2} \max }$ and aerobic scope in mammals. Biology Letters, 3, 99 102.

Gillooly, J.F., Allen, A.P., Savage, V.M., Charnov, E.L., West, G.B. \& Brown, J.H. (2006) Response to Clarke and Fraser: effects of temperature on metabolic rate. Functional Ecology, 20, 400-404.

Gillooly, J.F., Brown, J.H., West, G.B., Savage, V.M. \& Charnov, E.L. (2001) Effects of size and temperature on metabolic rate. Science, 293, 2248-2251.
Glazier, D.S. (2005) Beyond the '3/4-power law': variation in the intra- and interspecific scaling of metabolic rate in animals. Biological Reviews, 80, $1-$ 52.

Gonzalez, N.C., Kirkton, S.D., Howlett, R.A., Britton, S.L., Koch, L.G., Wagner, H.E. \& Wagner, P.D. (2006) Continued divergence in $\dot{\mathrm{V}}_{\mathrm{O}_{2} \max }$ of rats artificially selected for running endurance is mediated by greater convective blood $\mathrm{O}_{2}$ delivery. Journal of Applied Physiology, 101, 1288-1296.

González-Alonso, J., Teller, C., Andersen, S.L., Jensen, F.B., Hyldig, T. \& Nielsen, B. (1999) Influence of body temperature on the development of fatigue during prolonged exercise in the heat. Journal of Applied Physiology, 86, 1032-1039.

Halsey, L.G., Butler, P.J. \& Blackburn, T.M. (2006) A phylogenetic analysis of the allometry of diving. American Naturalist, 167, 276-287.

Harvey, P.H. \& Pagel, M.D. (1991) The Comparative Method in Evolutionary Biology. Oxford University Press, New York.

Hayssen, V. \& Lacy, R.C. (1985) Basal metabolic rates in mammals: taxonomic differences in the allometry of BMR and body mass. Comparative Biochemistry and Physiology A, 81, 741-754.

Heinrich, B. (1993) The Hot-blooded Insects. Strategies and Mechanisms of Thermoregulation. Harvard University Press, Cambridge.

Hinds, D.S. \& Rice-Warner, C.N. (1992) Maximum metabolism and aerobic capacity in heteromyid and other rodents. Physiological Zoology, 65, 188214.

Hinds, D.S., Baudinette, R.V., Macmillen, R.E. \& Halpern, E.A. (1993) Maximum metabolism and the aerobic factorial scope of endotherms. Journal of Experimental Biology, 182, 41-56.

Jones, J.H. (1998a) Optimization of the mammalian respiratory system: symmorphosis versus single species adaptation. Comparative Biochemistry and Physiology B, 120, 125-138.

Jones, J.H. (1998b) Symmorphosis and the mammalian respiratory system: what is optimal and does it exist? Principles of Animal Design: the Optimization and Symmorphosis Debate (eds E.R. Weibel, C.R. Taylor \& L. Bolis), pp. 241-248. Cambridge University Press, Cambridge.

Jones, J.H., Taylor, C.R., Lindholm, A., Straub, R., Longworth, K.E. \& Karas, R.H. (1989) Blood gas measurements during exercise: errors due to temperature correction. Journal of Applied Physiology, 67, 879-884.

Kabat, A.P., Rose, R.W. \& West, A.K. (2003) Non-shivering thermogenesis in a carnivorous marsupial Sarcophilus harrisii, in the absence of UCP1. Journal of Thermal Biology, 28, 413-420.

Kabat, A.P., Rose, R.W. \& West, A.K. (2004) Molecular identification of uncoupling proteins 2 and 3 in a carnivorous marsupial, the Tasmanian devil (Sarcophilus harrisii). Physiological and Biochemical Zoology, 77, 109-115.

Kabat, A.P., Rose, R.W. \& West, A.K. (2007) Shivering, muscle tone, and uncoupling proteins in a developing marsupial, the Tasmanian bettong (Bettongia gaimardi). Journal of Thermal Biology, 32, 282-292.

Killen, S.S., Costa, I., Brown, J.A. \& Gamperl, A.K. (2007) Little left in the tank: metabolic scaling in marine teleosts and its implications for aerobic scope. Proceedings of the Royal Society B, 274, 431-438.

Kristan, D.M. \& Hammond, K.A. (2004) Aerobic performance of wild-derived house mice does not change with cold exposure or intestinal parasite infection. Physiological and Biochemical Zoology, 77, 440-449.

Langsetmo, I., Weigle, G.E., Fedde, M.R., Erickson, H.H., Barstow, T.J. \& Poole, D.C. (1997) $\mathrm{VO}_{2}$ kinetics in the horse during moderate and heavy exercise. Journal of Applied Physiology, 83, 1235-1241.

Lindinger, M.I. (1999) Exercise in the heat: thermoregulatory limitations to performance in humans and horses. Canadian Journal of Applied Physiology, 24, 152-163.

Lindstedt, S.L. \& Conley, K.E. (2001) Human aerobic performance: too much ado about limits to $\mathrm{VO}_{2}$. Journal of Experimental Biology, 204, 3195-3199.

Lovegrove, B.G. (2000) The zoogeography of mammalian basal metabolic rate. American Naturalist, 156, 201-219.

Marti, B. \& Howald, H. (1990) Long-term effects of physical training on aerobic capacity: controlled study of former elite athletes. Journal of Applied Physiology, 69, 4151-1459.

McKechnie, A.E. \& Wolf, B.O. (2004) The allometry of avian basal metabolic rate: good predictions need good data. Physiological and Biochemical Zoo$\log y, 77,502-521$.

McKechnie, A.E., Freckleton, R.P. \& Jetz, W. (2006) Phenotypic plasticity in the scaling of avian basal metabolic rate. Proceedings of the Royal Society B, 273, 931-937.

McNab, B.K. (1988) Complications inherent in scaling the basal rate of metabolism in mammals. Quarterly Review of Biology, 63, 25-54.

Pagel, M. (1999) Inferring the historical patterns of biological evolution. Nature, 401, 877-884.

Pasquis, P., Lacaisse, A. \& Dejours, P. (1970) Maximal oxygen uptake in 4 species of small mammals. Respiration Physiology, 9, 298-309. 
Reidy, S.P., Nelson, J.A., Tang, Y. \& Kerr, S.R. (1995) Post-exercise metabolic rate in Atlantic cod and its dependence upon the method of exhaustion. Journal of Fish Biology, 47, 377-386.

Rezende, E.L., Bozinovic, F. \& Garland, T. Jr. (2004) Climatic adaptation and the evolution of basal and maximum rates of metabolism in rodents. Evolution, 58, 1361-1374.

Rezende, E.L., Garland, T. Jr., Chappell, M.A., Malisch, J.L. \& Gomes, F.R. (2006) Maximum aerobic performance in lines of Mus selected for high wheel-running activity: effects of selection, oxygen availability and the minimuscle phenotype. Journal of Experimental Biology, 209, 115-127.

Richardson, R.S., Leigh, J.S., Wagner, P.D. \& Noyszewski, E.A. (1999) Cellular $\mathrm{PO}_{2}$ as a determinant of maximal mitochondrial $\mathrm{O}_{2}$ consumption in trained human skeletal muscle. Journal of Applied Physiology, 87, 325-331.

Riisgård, H.U. (1998) No foundation of a ‘3/4 power scaling law' for respiration in biology. Ecology Letters, 1, 71-73.

Rose, R.W., West, A.K., Ye, J.M., Mccormack, G.H. \& Colquhoun, E.Q. (1999) Nonshivering thermogenesis in a marsupial (the Tasmanian bettong Bettongia gaimardi) is not attributable to brown adipose tissue. Physiological and Biochemical Zoology, 72, 699-704.

Savage, V.M., Gillooly, J.F., Woodruff, W.H., West, G.B., Allen, A.P., Enquist, B.J. \& Brown, J.H. (2004) The predominance of quarter-power scaling in biology. Functional Ecology, 18, 257-282.

Schaeffer, P.J., Hokanson, J.F., Wells, D.J. \& Lindstedt, S.L. (2001) Cold exposure increases running $\dot{\mathrm{V}}_{\mathrm{O}_{2} \text { max }}$ and cost of transport in goats. American Journal of Physiology, 280, R42-R47.

Schaeffer, P.J., Villarin, J.J. \& Lindstedt, S.L. (2003) Chronic cold exposure increases skeletal muscle oxidative structure and function in Monodelphis domestica, a marsupial lacking brown adipose tissue. Physiological and Biochemical Zoology, 76, 877-887.

Schaeffer, P.J., Villarin, J.J., Pierotti, D.J., Kelly, D.P. \& Lindstedt, S.L. (2005) Cost of transport is increased after cold exposure in Monodelphis domestica: training for inefficiency. Journal of Experimental Biology, 208, 31593167 .

Schwerzmann, K., Hoppeler, H., Kayar, S.R. \& Weibel, E.R. (1989) Oxidative capacity of muscle and mitochondria: correlation of physiological, biochemical, and morphometric characteristics. Proceedings of the National Academy of Sciences of the United States of America, 86, 1583-1587.

Seeherman, H.J., Taylor, C.R., Maloiy, G.M.O. \& Armstrong, R.B. (1981) Design of the mammalian respiratory system. II. Measuring maximum aerobic capacity. Respiration Physiology, 44, 11-23.

Spriet, L.L., Gledhill, N., Froese, A.B. \& Wilkes, D.L. (1986) Effect of graded erythrocythemia on cardiovascular and metabolic responses to exercise. Journal of Applied Physiology, 61, 1942-1948.

Suarez, R.K. (1996) Upper limits to mass-specific metabolic rates. Annual Review of Physiology, 58, 583-605.

Swallow, J.G., Garland, T. Jr., Carter, P.A., Zhan, W.-Z. \& Sieck, G.C. (1998)
Effects of voluntary activity and genetic selection on aerobic capacity in house mice (Mus domesticus). Journal of Applied Physiology 84, 69-76.

Taylor, C.R. (1987) Structural and functional limits to oxidative metabolism: insights from scaling. Annual Review of Physiology, 49, 135-146.

Turner, D.L., Hoppeler, H., Hokanson, J. \& Weibel, E.R. (1995) Cold acclimation and endurance training in guinea pigs: changes in daily and maximal metabolism. Respiration Physiology, 101, 183-188.

Walton, B.M. (1993) Physiology and phylogeny: the evolution of locomotor energetics in hylid frogs. American Naturalist, 141, 26-50.

Weibel, E.R. (2000) Symmorphosis: on Form and Function in Shaping Life. Harvard University Press, Cambridge.

Weibel, E.R. \& Hoppeler, H. (2005) Exercise-induced maximal metabolic rate scales with muscle aerobic capacity. Journal of Experimental Biology, 208, $1635-1644$

Weibel, E.R., Bacigalupe, L.D., Schmidt, B. \& Hoppeler, H. (2004) Allometric scaling of maximal metabolic rate in mammals: muscle aerobic capacity as a determinant factor. Respiration Physiology and Neurobiology, 140, 115-132.

Weibel, E.R., Taylor, C.R. \& Hoppeler, H. (1991) The concept of symmorphosis: a testable hypothesis of structure-function relationship. Proceedings of the National Academy of Sciences of the United States of America, 88, 1035710361.

West, G.B., Brown, J.H. \& Enquist, B.J. (1997) A general model for the origin of allometric scaling laws in biology. Science, 276, 122-126.

White, C.R. \& Seymour, R.S. (2005a) Allometric scaling of mammalian metabolism. Journal of Experimental Biology, 208, 1611-1619.

White, C.R. \& Seymour, R.S. (2005b) Sample size and mass range effects on the allometric exponent of basal metabolic rate. Comparative Biochemistry and Physiology A, 142, 74-78.

White, C.R., Cassey, P. \& Blackburn, T.M. (2007) Allometric exponents do not support a universal metabolic allometry. Ecology, 88, 315-323.

White, C.R., Matthews, P.G.D. \& Seymour, R.S. (2006a) Balancing the competing requirements of saltatorial and fossorial specialisation: burrowing costs in the spinifex hopping mouse, Notomys alexis. Journal of Experimental Biology, 209, 2103-2113.

White, C.R., Phillips, N.F. \& Seymour, R.S. (2006b) The scaling and temperature dependence of vertebrate metabolism. Biology Letters, 2, 125-127.

Wingo, J.E. \& Cureton, K.J. (2006) Body cooling attenuates the decrease in maximal oxygen uptake associated with cardiovascular drift during heat stress. European Journal of Applied Physiology, 98, 97-104.

Wu, Z.D., Puigserver, P., Andersson, U., Zhang, C.Y., Adelmant, G., Mootha, V., Troy, A., Cinti, S., Lowell, B., Scarpulla, R.C. \& Spiegelman, B.M. (1999) Mechanisms controlling mitochondrial biogenesis and respiration through the thermogenic coactivator PGC-1. Cell, 98, 115-124.

Received 2 November 2007; accepted 15 February 2008

Handling Editor: Michael Angilletta 